much publicity lately of Susanne Dell's work (1980) demonstrating the large numbers of Special Hospital patients awaiting transfer to NHS hospitals: that the number of such patients is growing and the waiting period longer. In Broadmoor at the last count we had 51 patients who should no longer be there.

\section{Brosdmoor's future}

These are some of the problems facing us today, as if we do not have enough in simply considering patients for admission, treating them and assessing them for discharge. As to the future, any new legislation dealing with consent to treatment for detained patients might seriously affect us, but Broadmoor has never asked to be treated differently from other hospitals except on grounds of security. We shall have problems over the next few years when several of our most senior consultants retire, including Dr McGrath, and they will be difficult to replace. We shall deal with all the diffculties inherent in replacing an ancient monument with a purpose-built modern hospital with many fewer beds but which will relieve our terrible overcrowding, commented on by the Estimates Committee of the House of Commons in 1968, the Hospital Advisory Service in 1974 and the Butler Committee in 1975. Lastly, my personal view is that Broadmoor has a public relations problem caused by the 'can't win' phenomenon. We either let them out too soon or keep them in too long, or we let the wrong ones out, and so on. I believe we must develop an effective publicity machine to show the public, and indeed the profession, what our problems are. We invite psychiatrists everywhere to help us to solve them.

REFERENCES

allderidge, Patricia (1977) In Daniel McNaughton: His Trial and the Aftermath ed. West, D. J. \& Walk, A. London: Gaskell Books.

DelL, SusanNe (1980) Transfer of Special Hospital patients to the NHS. British Journal of psychiatry, 136, 222-34.

PARTRIDGE, R. (1953) Broadmoor. London: Chatto and Windus.

WALKER, N. and MCCABE, S. (1973) Crime and Insanity in England, Vol. 2 Edinburgh University Press.

The views expressed in this paper are those of the author and do not necessarily reflect those of the Department of Health and Social Security.

\title{
Broadmoor's Relationship with NHS Psychiatric Hospitals
}

\author{
By K. Loucas, Consultant Psychiatrist, Broadmoor Hospital
}

Just after the First World War, in 1919, and before the more recent legislation that has shaped the philosophy of this hospital, one Ronald True was sentenced to death for the killing of a young woman from Fulham. The records described her as 'handsome'. (She may have been a prostitute.) The public was outraged when the Home Secretary of the day, on receiving the statutory Medical Certificates, ordered a reprieve and Ronald True came to Broadmoor Hospital. Here he passed his time writing doggerel and lyrics to old and popular tunes. One of these, sung to the tune of 'John Brown's Body' goes:

'There is a piace in Berkshire

Where the lunatics reside

It's called the British Bastille

And it's famous far and wide.'

As you made your approach up the hill and perhaps tried to gain entry, you will no doubt have been impressed by the architecture: Prison Baroque. Inside, closed doors and jingling keys are constant reminders that it is a different world. But it is not a prison. As Dr Hamilton has explained, it has never been a prison. For all its high walls, locked doors and limited freedom, it is and always has been a hospital; and since 1948 part of that same National Health Service which we all enjoy. Different it is, special it certainly is.

One of the most important British contributions to psychiatry has been the 1959 Mental Health Act. It changed the relationship between the alienists and the public. With the help of the boom in psycho-pharmacology it changed the unacceptable face of psychiatry. It threw away baby, bath water and the bath. Turnover of patients and discharge became the name of the game. Straight line graphs gave a prediction of zero-need for Asylums. Plans for closing the big institutions gave rise to the inevitable planning blight. Everybody went into the Community.

There is much to be done: out-patient clinics, day hospital, domiciliary visits, lectures, meetings and so on. Last week I was asked to see a patient at one such erstwhile Lunatic Asylum-come Mental Hospital, now 'Therapeutic Community'. Having enquired after the doctor who had requested the consultation, I learned that he came on Wednesday mornings-not to the ward but to the hospital. His task, clearly, is an impossible one with 200 in-patients and all the associated organizational responsibilities.

The Guardian headlines in August last year (not front page but prominent enough) carried a caption that read 'Open door-Open mind'. The article told how the scandal of delays in getting proper treatment (in the Community) had been solved. Lewisham had been provided with a Selfreferral Walk-in Clinic. All part of this most worthy, highly laudable service to the Community. Community care in the 
words of the schoolboy classic 'is a good thing'. But at a price. At a cost to those not so ideally placed. The doors are revolving and the hospitals have not closed. There are now accumulating the 'new long-stay' patients. Not only in the Community-based hospitals themselves, but in the Special Hospitals now cast in the role of the 'Back Wards'.

There has been a shift of emphasis and a change of attitude. Time and resources are limited. Thus the abandonment of closed wards has put an obvious limit on the service to be provided. Familiarity with disturbed patients is not possible, and essential expertise is lost. Worse-value judgements replace clinical assessments. Professionalism is sacrificed on the altar of the (so called) Multidisciplinary Team. All teams require discipline and in this area of their function the teams are anarchic. Thus the warnings of a Ministry of Health circular of 1959 have gone unheeded. Despite a succession of reports (various Estimate Committees, HAS pronouncements and the Butler Report) the Prisons, Area Mental Hospitals and Special Hospitals are engaged in a clumsy game of Pass the Parcel: be it the inadequate personality, chronic schizophrenic or whatever.

This afternoon, Dr Tidmarsh will be regaling us with redhot news from his computer terminals. Evidence proving something we have all been painfully aware of for some time. Things were bad and they are getting worse. The Special Hospitals are overcrowded, as everyone freely admits. There would seem to be an ever-increasing need for patients to receive treatment under conditions of Security. At the same time, it is becoming increasingly difficult to effect the proper discharge of patients from the Special Hospitals on transfer to the appropriate Catchment Area Mental Hospital. This whole process has been the subject of an extensive and detailed research project by Susanne Dell of the Institute of Psychiatry in London, financed by the DHSS. Her findings are presented in the British Journal of Psychiatry (March $1980,136,222-34)$ and also in the form of a Special Hospital Research Report No. 16. Reviewing how patients are transferred from the Special Hospitals, she identified some of the problems, examined individual factors contributing to the difficulties and hinted at ways in which they could be overcome. Her survey concentrated on patient movement in 1976. Taken together with David Tidmarsh's observations, it is clear that whilst there have been a series of swings the general trend is towards an inexorable slow-down. The numbers actually transferred from Broadmoor Hospital to area mental hospitals has decreased dramatically. Some patients are having to wait longer and longer before a transfer is effected: up to 6 years from the date when an application for a bed in a Community-based hospital is first made. A point to be emphasised: 4 to 6 years after a particular patient is no longer in need of treatment under conditions of Security and well enough for placement in an open ward, he remains confined. For years these patients continue to be deprived of an opportunity to take up their lives and responsibilities in the Community.
When I first came to Broadmoor some ten years ago, there was (for us here) a fairly brisk turnover. Approximately 150 left and 150 came in (more or less). I would write to the particular Consultant, who would come, examine the patient and then over lunch clarify aspects of clinical concern. Without further delay he would accept the patient for transfer. Account must here be taken of the fact that the DHSS, as Managers, scrutinize and also ultimately give authority for such moves in consultation with the relevant RHA. Things have changed. In the wake of the all too familiar reports arising out of allegations, complaints and scandals, the Area Mental Hospitals sought to improve their image. Wards were upgraded: they needed redecorating, so there was a shortage of beds (but for how long?). Then there were not enough nurses to man these redecorated Wards. If you persevered with your request, the Consultant did come, eventually; but now with a nurse. The next stage was for the Consultant to come with his team. Still all good Community psychiatry. But the team came to include a Union Representative. This Union Representative came not to take part in a clinical assessment but to exercise political control. One such group which came not only included the Union Representative but brought along the nurse/victim from the patient's previous admission. Presumably we now were getting a personal/emotional judgement as well as a political one. But there was worse to come even yet. The doctor and nursing team no longer travel together, so discussions only occur later, at some formal meeting. Then the doctor stopped coming. Now, sadly, no-one wants to come.

Susanne Dell has listed the various reasons given for refusing an application for the transfer of a patient:

1. No room: most common and, as she says, it is worse in the field of the mentally handicapped and severely subnormal.

2. Patients' characteristics: past behaviour (arson, absconding) and history of assaults; or quibbles about diagnosis (schizophrenic or psychopath?).

3. Staff refusal: lack of proper facilities, demands for extra pay, later embroidered with a simple exclusion list.

4. Lack of security/closed wards.

5. Lack of facilities: no long-stay wards; no facilities for rehabilitation.

6. Disputed catchment areas.

And all this is about a patient who would appear to have been duly processed by a clinical team here at Broadmoor Hospital and cleared by the DHSS together with the Home Office, but still stigmatized by the Broadmoor label. One of the verses of Ronald True's songs goes:

'Some say you can't get out at all

I don't mind telling you

Someone got his liberty

In eighteen sixty two.'

The relationship between this Unit and the Area Mental Hospitals is simple, direct and mutually dependent. Both are 
manned by professionals with clear duty and responsibility to provide comprehensive care for those in need. It is my opinion that in large part problems have occurred because the Consultant is not accepted as the leader of his clinical team. Another factor would appear to be confusion, both clinical and legal. The patient is seen only in terms of what his behaviour was, not how his clinical condition presents now. This is further compounded by a semantic game whereby the chronic schizophrenic of 15 to 20 years standing becomes 'a psychopath' and therefore no-one's responsibility. The application of Section 65 to the Hospital Order does not require the hospital or the Responsible
Medical Officer to provide 'Security'. Further Home Office involvement does not in fact impede clinical freedom, but merely underlines the element of responsibility. My plea is for extended professional contact to restore mutual trust and confidence so that we do, in fact, continue to provide a National Health Service. Paraphrasing Prospero:

'For these here confined by you

Let your indulgence set them free'.

The views expressed in this paper are those of the author and do not necessarily reflect those of the Department of Health and Social Security.

\title{
Trends in Length of Stay at Broadmoor
}

\author{
by David Tidmarsh, Consultant Psychiatrist, Broadmoor Hospital
}

Little information is available about how long patients stay in the Special Hospitals. This paper describes what is believed to be the first systematic study of this topic.

The inquiry started when I was looking into how best to monitor the overall success and failure rates of treatment at Broadmoor. Because the hospital deals with a long-stay population of patients, whose relapses into serious violence after leaving the hospital are happily rare and often long delayed, it was felt essential to start with the largest possible sample, and this meant starting with patients admitted many years ago. Though a great deal of data on these patients is to be found in their case notes, it would not have been possible to extract this with our present resources. The only alternative source of information available at the beginning of the study was the hospital's admission and discharge registers. These give for each day of the year the names of the patients admitted and discharged. Included are each patient's hospital number, sex, reference to previous admissions, the method of separation* and the address to which he or she went. As it happens, the results of a hospital census taken in 1960 were also available from which, without too much trouble, it was possible to discover who was in the hospital on 1 January 1960 a very convenient starting point shortly before the implementation of the 1959 Mental Health Act. These two sources of data thus made it possible to identify for follow-up purposes all patients in the hospital on 1 January 1960 and all patients admitted and leaving thereafter. It was at this point realized that these meagre data could usefully be analysed to give information about how

* 'Separation' refers to leaving hospital by any method. long these patients stayed, and it is this analysis which is reported here.

Using safeguards about confidentiality similar to those used by the Special Hospitals Research Unit's Case Register, the hospital registers were transcribed and information about each patient then coded onto unidentifiable data sheets and punched onto cards. The data were analysed with the help of an SPSS programme written by myself which made it possible to make a complete reconstruction of the patient population from 1 January 1960 up to 31 December 1979. From this it was possible to select admission and discharge cohorts and also to identify census population at any convenient date and to calculate periods between various events. Errors have not been entirely eliminated, though more obvious ones have been removed after simple inspection of a computer print-out of the data, and others by inspecting basic tabulations. There remains a discrepancy of less than $\frac{1}{2}$ per cent between the statistics generated by the computer and the hospital's statistics compiled manually. These errors do not significantly affect the present results and will be corrected in due course.

\section{Results}

Admissions to Broadmoor almost trebled in the five years after the implementation of the Mental Health Act; they then remained at the level of about 150 patients a year. But since 1971 there has been a steady fall almost back to the figure for 1960.

The proportion of each year's admission cohort discharged in a given period has changed remarkably little over the last 20 years. Though the proportion leaving within five 